\title{
Effects of a functional COMT polymorphism on brain anatomy and cognitive function in adults with velo-cardio-facial syndrome
}

\author{
T. van Amelsvoort ${ }^{1 *}$, J. Zinkstok1 ${ }^{1}$, M. Figee ${ }^{1}$, E. Daly ${ }^{2}$, R. Morris ${ }^{2}$, M. J. Owen ${ }^{3}$, K. C. Murphy' \\ L. De Haan ${ }^{1}$, D. H. Linszen ${ }^{1}$, B. Glaser ${ }^{3}$ and D. G. M. Murphy ${ }^{2}$ \\ ${ }^{1}$ Department of Psychiatry, Academic Medical Centre, Amsterdam, The Netherlands \\ ${ }^{2}$ Department of Psychological Medicine, Institute of Psychiatry, King's College London, London, UK \\ ${ }^{3}$ Department of Psychological Medicine, Cardiff University, Cardiff, UK
}

\begin{abstract}
Background. Velo-cardio-facial syndrome (VCFS) is associated with deletions at chromosome 22q11, abnormalities in brain anatomy and function, and schizophrenia-like psychosis. Thus it is assumed that one or more genes within the deleted region are crucial to brain development. However, relatively little is known about how genetic variation at 22q11 affects brain structure and function. One gene on 22q11 is catechol-O-methyltransferase (COMT): an enzyme that degrades dopamine and contains a functional polymorphism ( $\left.\mathrm{Val}^{158} \mathrm{Met}\right)$ affecting enzyme activity. Here, we investigated the effect of COMT $\mathrm{Val}^{158} \mathrm{Met}$ polymorphism on brain anatomy and cognition in adults with VCFS.
\end{abstract}

Method. The COMT Val ${ }^{158}$ Met polymorphism was genotyped for 26 adults with VCFS on whom DNA was available. We explored its effects on regional brain volumes using hand tracing approaches; on regional grey- and white-matter density using computerized voxel-based analyses; and measures of attention, IQ, memory, executive and visuospatial function using a comprehensive neuropsychological test battery.

Results. After corrections for multiple comparisons Val-hemizygous subjects, compared with Met-hemizygotes, had a significantly larger volume of frontal lobes. Also, Val-hemizygotes had significantly increased grey matter density in cerebellum, brainstem, and parahippocampal gyrus, and decreased white matter density in the cerebellum. No significant effects of COMT genotype on neurocognitive performance were found.

Conclusions. COMT genotype effects on brain anatomy in VCFS are not limited to frontal regions but also involve other structures previously implicated in VCFS. This suggests variation in COMT activity is implicated in brain development in VCFS.

Received 19 October 2006; Revised 21 March 2007; Accepted 30 March 2007; First published online 10 May 2007

Key words: Cognition, COMT, MRI, VCFS, 22q11.

\section{Introduction}

Velo-cardio-facial syndrome (VCFS) is a genetic disorder associated with microdeletions at chromosome 22q11 (Shprintzen et al. 1978), typical facial morphology, cardiovascular anomalies, velopharyngeal insufficiencies, mild to borderline learning disabilities, cognitive deficits and a high prevalence of psychiatric disorders including ADHD (Papolos et al. 1996) and schizophrenia-like psychosis (Murphy et al. 1999). This high prevalence of psychiatric disorders is likely to be caused by haploinsufficiency of one or more genes on $22 \mathrm{q} 11$.

* Address for correspondence: T. van Amelsvoort, M.D., Department of Psychiatry, Academic Medical Centre, Tafelbergweg 25, 1105 BC, Amsterdam, The Netherlands.

(Email: t.a.vanamelsvoort@amc.uva.nl)
One of the candidate genes located at 22q11 is the gene for catechol-O-methyltransferase (COMT), an enzyme that degrades dopamine. Particularly in the prefrontal cortex (PFC) degradation of dopamine is largely dependent on activity of COMT, whereas in other brain regions degradation of dopamine is mainly by monoamino-oxidase (MAO) and the dopamine transporter (DAT) (Chen et al. 2004). A common mutation in the COMT gene, leading to an amino acid substitution [Valine ( $\mathrm{Val})$ to Methionine (Met)] results in decreased enzymatic activity with the Met/Met variant of COMT showing $40 \%$ less enzymatic activity than the $\mathrm{Val} / \mathrm{Val}$ variant (Lachman et al. 1996; Chen et al. 2004).

The COMT $\mathrm{Val}^{158} \mathrm{Met}$ polymorphism has been reported to: (1) affect midbrain tyrosine hydroxylase levels and dopamine synthesis (Akil et al. 2003); 
(2) modulate dopaminergic interactions between the PFC and the midbrain (Meyer-Lindenberg et al. 2005; Smolka et al. 2005); and (3) affect cognitive functions dependent on PFC, including working memory and attention (Egan et al. 2001; Malhotra et al. 2002; MeyerLindenberg et al. 2005). People with VCFS carry only one copy of the COMT allele on their intact chromosome. It has been suggested that dopaminergic neurotransmission in VCFS is compromised, thereby increasing susceptibility for psychosis (Dunham et al. 1992). Therefore studying the COMT Val ${ }^{158}$ Met polymorphism in VCFS may increase our understanding of brain development and predisposition for psychosis in this population.

An increasing number of studies have investigated the effects of the COMT Val ${ }^{158}$ Met polymorphism on cognitive function in people with VCFS. Some have reported that in VCFS children the low-activity Met allele is associated with better performance on prefrontal-dependent cognitive tasks (Bearden et al. 2004; Shashi et al. 2006). However Glaser et al. (2006) reported no difference on tasks of executive function between Met-hemizygous and Val-hemizygous groups in a combined children/adult VCFS population. In addition the COMT $\mathrm{Val}^{158} \mathrm{Met}$ polymorphism may affect overall cognitive ability. For example, some studies have reported that the Met allele is associated with a decline in verbal IQ (Gothelf et al. 2005), and poorer performance on a task of language expression and spatial working memory (Baker et al. 2005); whereas others found the Met allele to be associated with higher verbal IQ (Shashi et al. 2006). Thus the effect of COMT $\mathrm{Val}^{158} \mathrm{Met}$ polymorphism and cognitive function in people with VCFS is not easily understood, and the discrepancy in results of the reported studies may have arisen because of differences in dopaminergic neurotransmission due to developmental changes during adolescence, since both children, adolescents, and young adults were included in the study populations (Wahlstrom et al. 2007). The only study to date on COMT $\mathrm{Val}^{158} \mathrm{Met}$ polymorphism in adults with VCFS showed that those with the Met allele displayed more severe excitement symptoms, and worse performance on theory of mind, Trails B, olfactory identification, communication and social functioning compared with those with the $\mathrm{Val}$ allele (Bassett et al. 2007). However, thus far there is no evidence that the COMT Val ${ }^{158}$ Met polymorphism affects the prevalence of schizophrenia in adults with VCFS (Bassett et al. 2007; Murphy et al. 1999).

The effects of the COMT $\mathrm{Val}^{158} \mathrm{Met}$ polymorphism on brain anatomy in people with VCFS have been less frequently reported, but Gothelf et al. (2005) found the Met allele was associated with a smaller frontal lobe volume. Others, however (Kates et al. 2006), did not find an effect of the COMT $\mathrm{Val}^{158} \mathrm{Met}$ polymorphism alone, but did observe a gender-moderated effect of COMT genotype on both frontal lobe anatomy but not on frontal-lobe-dependent cognitive tasks.

Thus to date there have been relatively few studies on the effect of COMT $\mathrm{Val}^{158} \mathrm{Met}$ polymorphism in people with VCFS, and those which are available focused on children and adolescents. Hence, it is unclear how the COMT $\mathrm{Val}^{158} \mathrm{Met}$ polymorphism affects brain anatomy and cognitive function in adults with VCFS - and especially in adults. It has been suggested that PFC dopamine levels peak during adolescence and decline thereafter (Andersen et al. 1997), and that COMT activity reaches its optimal levels in early adulthood in the PFC, which might explain the discrepancies in studies on COMT $\mathrm{Val}^{158} \mathrm{Met}$ polymorphism in children, adolescents and young adults with VCFS (Tunbridge et al. 2006). We previously reported on brain anatomy and cognitive function in an adult VCFS population (van Amelsvoort et al. 2004a,b). We have retrospectively obtained COMT genotype data from this sample. Here, we explore the relationship between COMT $\mathrm{Val}^{158} \mathrm{Met}$ polymorphism and (1) brain morphometry and (2) measures of intelligence, attention, working memory, visuospatial function and memory in adults with VCFS. Because COMT is also expressed in abundance in non-frontal brain regions (Tunbridge et al. 2006), we tested the hypothesis that in adults with VCFS, genetic variation in COMT activity is associated with anatomical differences in frontal brain regions but also in other regions including cerebellum, regions which have been implicated in VCFS in previous studies. We further hypothesized that, in agreement with Bassett et al. (2007), in adults with VCFS those who were Val-hemizygous would perform better on frontal cognitive tests.

\section{Method}

\section{Subjects}

The study was approved by the local Ethics Committee and after complete description of the study to the subjects, written informed consent was obtained from themselves and/or their carers. All subjects were screened for medical conditions affecting brain functioning using a semi-structured clinical interview and routine clinical blood tests. To establish a DSM-IV (APA, 1994) diagnosis a semi-structured psychiatric interview was performed [Schedule for Clinical Assessment in Neuropsychiatry (SCAN); Wing et al. 1990] as described elsewhere (Murphy et al. 1999). We included 26 subjects with clinical features of VCFS and an established 22q11 deletion who have participated in a previously reported study on brain anatomy 
and/or cognitive function in VCFS (Van Amelsvoort et al. 2004a,b). Twelve subjects had psychosis, five val-hemizygotes and seven met-hemizygotes, were clinically stable and taking antipsychotic medication. No other psychiatric disorders were present in the 26 subjects with VCFS.

\section{Genetics}

Blood samples were collected from 26 participants, and DNA was extracted. Fluorescence in situ hybridization (FISH) was used to detect a 22q11 deletion (Oncor Inc., Gaithersburg, MD). The COMT Val ${ }^{158} \mathrm{Met}$ polymorphism was genotyped using the SNaPshot technique of single base extension (Applied Biosystems, Foster City, CA, USA) according to manufacturer's instructions. The initial PCR reaction was performed using a Touchdown-PCR-protocol, with the following primers: forward: 5'-ACTGTGGCTACTCAGCTGTG-3' and reverse: 5'-CCTTTTTCCAGGTCTGACAA-3'. The allele at the SNP position was determined by use of a $30 \mathrm{bp}$ extension primer (5'-ATCACCCAGCGGATGGTGGATTTCGCTGGC-3'). All alleles were resolved on an ABI 3100 sequencer (Applied Biosystems, Foster City, CA, USA).

\section{Magnetic resonance imaging acquisition and measurements}

Magnetic resonance imaging (MRI) of the brain was performed on a 1.5-T MRI system (Signa; General Electric Co, Milwaukee, WI, USA) at the Maudsley Hospital, London, UK. A coronal volumetric spoiled gradient acquisition in the steady state dataset covering the whole head was acquired (repetition time, $13.8 \mathrm{~ms}$; echo time, $2.8 \mathrm{~ms} ; 124$ sections; $1.5-\mathrm{mm} \mathrm{sec-}$ tion thickness). This dataset was used to perform manual tracing of brain volumes, using Measure software (Barta et al. 1997). Volumetric analysis by manual tracing was performed for total intracranial volume, caudate, putamen, hippocampus, amygdala, frontal, occipito-parietal and temporal lobes, cerebellum and ventricular and peripheral cerebrospinal fluid (CSF) by means of region of interest boundaries as previously described (Murphy et al. 1992, 1993a,b; Van Amelsvoort et al. 2001, 2004a). The volume of each region was calculated by multiplying the summed pixel cross-sectional areas by section thickness. Intra-rater and inter-rater reliabilities (range, 0.90-0.99) were determined by intra-class correlation computation for all brain regions traced by two operators and were highly significant $(F>4.0$ and $p<0.002$ ).

In addition, for determination of grey and white matter densities we carried out voxel based morphometry on a second dataset that we acquired in the same individuals: a whole brain near axial dual-echo fast spin-echo (FSE) dataset aligned with the anterior commissure (AC)-posterior commissure (PC) plane [relaxation time $(\mathrm{TR})=4000 \mathrm{~ms}$, effective echo time $(\mathrm{TE})=20$ and $85 \mathrm{~ms}, 3 \mathrm{~mm}$ slice thickness]. This dataset was used to examine between-group differences in grey and white matter volume using a previously published methodology (Sigmundsson et al. 2001; McAlonan et al. 2002; Van Amelsvoort et al. 2004a). Voxels representing extracerebral tissue were automatically set to zero (Suckling et al. 1999a) and the probability of each intracerebral voxel belonging to grey matter, white matter, CSF, or dura/vasculature tissue classes was then estimated by a modified fuzzy clustering algorithm (Suckling et al. 1999b). On the basis of prior results, we equated these probabilities to the proportional volumes of each tissue class in the often heterogeneous volume of tissue represented by each voxel (Bullmore et al. 1995). Thus, for example, if the probability of grey matter class membership was 0.8 for a given voxel, it was assumed that $80 \%$ of the tissue represented by that voxel was grey matter. Because the voxel size was predetermined $\left(2.2 \mathrm{~mm}^{3}\right)$, we then estimated the volume in millilitres of grey matter, white matter and CSF in each voxel. Summing these voxel tissue class volumes over all intracerebral voxels yielded global tissue class volumes. To allow estimation of between-group differences at each intracerebral voxel (spatial extent statistics), the short echo (proton-density-weighted) FSE images were coregistered using an affine transformation (Press et al. 1992; Brammer et al. 1997) with a template image in the coordinate system of standard space as defined by Talairach \& Tournoux (1988). This individually estimated transformation was then applied to each of that subject's grey and white tissue probability maps.

\section{Neuropsychological testing}

Overall intellectual functioning, memory, visuospatial and perceptual ability, executive functioning, and attention were measured. Details of the tests employed have been described elsewhere (Van Amelsvoort et al. $2004 b$ ) but the battery was chosen on suitability for a learning disabled population and addressing measures of overall IQ, attention, memory, executive function and visuospatial function. The test battery included: a short version of the Weschler Adult Intelligence Scale - Revised (WAIS-R; Wechsler, 1981) consisting of five subtests (Vocabulary, Comprehension, Similarities, Block Design and Object Assembly); the Doors and People Test of Visual and Verbal Recall and Recognition (Baddeley et al. 1994); two subtests from the Wechsler Memory Scale - Revised (WMS-R; Wechsler, 1987): the Logical Memory (immediate and 
delayed recall of two short stories) and Paired Associates (immediate and delayed recall of matched pairs) subtests; the Visual Space and Object Perception Battery (VOSP ; Warrington \& James, 1991); Computerised Tower of London Task (3-D CTL Test) (Shallice, 1982; Morris et al. 1988, 1990); Computerised Executive Golf Task (Morris et al. 1988; Baker et al. 1996) ; Controlled Oral Word Association Test (Benton \& Hamsher, 1976); Weigl test (Goldstein \& Scheerer, 1941); and the Continuous Performance Test (Conner, 1995).

\section{Statistics}

The study population was divided into two groups according to COMT genotype: val-hemizygous and met-hemizygous VCFS subjects. Differences in age, and IQ between the two groups were compared using a $t$ test; differences in gender and psychiatric diagnosis using a $\chi^{2}$ test.

Manually traced brain volumes, computerized tissue class volumes, and cognitive variables

Data were analysed with SPSS 12.0 for Windows (SPSS Inc., Chicago, IL). COMT effects on total and regional brain volumes, total tissue class volumes and cognitive variables were examined using a univariate analysis of covariance (ANCOVA) using COMT genotype, and gender as fixed factors and age and total intracranial volume (in case of MRI data) as covariates. We subsequently employed Bonferroni corrections for multiple testing using $p<0.0045$ for the manually traced volumes, $p<0.017$ for the tissue class volumes, and $p<0.0011$ for the cognitive variables as levels of statistical significance (two-tailed).

\section{Analysis of MRI data using computerized voxel-wise analysis}

Between-group differences in grey and white matter were localized by fitting an appropriate GLM at each intracerebral voxel. Inference was via a permutation distribution of spatial extent statistics with significance levels set to control for multiple comparisons by having less than one estimated false positive region (cluster) across the image $(p<0.001)$. In brief, the processing proceeded as follows. Maps of the standardized GLM model coefficient of interest (group) at each voxel were thresholded such that only voxels with probability $<0.05$ were retained. The sum of voxelwise statistics for each three-dimensional suprathreshold cluster was the test statistic, the sign indicating a relative excess or deficit in local tissue density. Significance testing of the clusters was performed using a null distribution of this test statistic similarly obtained after repeatedly randomly
Table 1. Characteristics of 26 adults with velo-cardio-facial syndrome

\begin{tabular}{lccc}
\hline & Val $(n=14)$ & Met $(n=12)$ & $p$ \\
\hline Age (yr \pm s.D.) & $30.3(10.6)$ & $37.33(10.6)$ & 0.10 \\
Gender, M/F & $6 / 8$ & $3 / 9$ & 0.43 \\
Psychosis & 5 & 7 & 0.43 \\
FSIQ ( \pm s.D.) & $71.7(10.6)$ & $72.32(13.2)$ & 0.90 \\
\hline
\end{tabular}

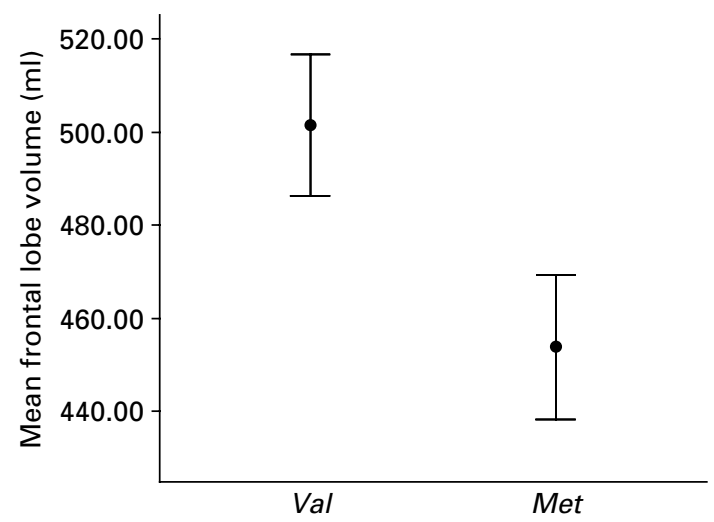

Fig. 1. Mean volumes (ml) of frontal lobes in Met hemizygous and $\mathrm{Val}$ hemizygous velo-cardio-facial syndrome people.

permuting the relevant factor in the GLM and refitting of the model (Bullmore et al. 1999).

\section{Results}

We studied 26 adults with VCFS. Data on age, gender, psychiatric diagnosis and intellectual function are presented in Table 1. Age, psychiatric diagnosis, full scale IQ (FSIQ) and gender did not differ between valand met-hemizygous groups. However, the women in our sample were significantly older than the men; therefore age was introduced as a covariate in our analyses. Psychiatric diagnosis and FSIQ did not vary as a function of gender. We were unable to acquire MRI scans on seven subjects and neuropsychological data on three subjects. There were no differences in age, psychiatric diagnosis, FSIQ or gender between val- and met-hemizygous subgroups with the MRI or the cognitive data.

\section{COMT effects on manually traced brain volumes}

After accounting for total intracranial volume and age there was a significant COMT effect on volumes of frontal $(F=30.09, \quad p=0.000)$, and temporal lobes $(F=10.17, p=0.007)$, cerebellum $(F=8.30, p=0.013)$; and peripheral CSF (CSF excluding ventricles) $(F=$ 10.84, $p=0.006$ ) (Fig. 1). There were no gender effects or COMT $\times$ gender interactions. No significant 
Table 2. Manually traced brain and computerized tissue class volumes in Val-hemizygous subjects and Met-hemizygous subjects (corrected for intracranial volume)

\begin{tabular}{|c|c|c|c|c|c|}
\hline \multirow[b]{2}{*}{ Brain structure } & \multicolumn{2}{|c|}{ Group mean (S.D.), ml } & \multirow[b]{2}{*}{$p$ value } & \multirow[b]{2}{*}{$F$} & \multirow[b]{2}{*}{$\mathrm{df}$} \\
\hline & $\operatorname{Val}(n=10)$ & $\operatorname{Met}(n=9)$ & & & \\
\hline Total intracranial volume & $1270.639(50.074)$ & $1314.991(55.782)$ & 0.571 & 0.337 & 1,14 \\
\hline Frontal lobes & 499.154 (5.479) & 454.957 (6.216) & $0.000^{* *}$ & 30.09 & 1,13 \\
\hline Occipitoparietal lobes & $365.178(11.253)$ & $363.977(12.766)$ & 0.946 & 0.005 & 1,13 \\
\hline Temporal lobes & $136.855(5.177)$ & $111.586(5.873)$ & $0.007^{*}$ & 10.17 & 1,13 \\
\hline Putamen & $6.632(0.468)$ & $7.140(0.497)$ & 0.473 & 0.548 & 1,12 \\
\hline Caudate & $7.967(0.422)$ & $7.588(0.449)$ & 0.552 & 0.375 & 1,12 \\
\hline Peripheral CSF & $126.961(11.793)$ & $184.760(13.377)$ & $0.006^{*}$ & 10.84 & 1,13 \\
\hline Hippocampus & $5.339(0.307)$ & $4.693(0.344)$ & 0.197 & 1.888 & 1,11 \\
\hline Amygdala & $4.467(0.329)$ & $4.032(0.368)$ & 0.406 & 0.746 & 1,11 \\
\hline Cerebellum & $109.859(3.621)$ & $95.740(4.108)$ & $0.013^{*}$ & 8.30 & 1,13 \\
\hline Ventricles & $0.995(0.543)$ & $2.623(0.616)$ & 0.074 & 3.768 & 1,13 \\
\hline \multicolumn{6}{|l|}{ Tissue class volumes } \\
\hline Total grey matter & $599.90(81.90)$ & 560 (101.49) & 0.31 & 1.15 & 1,11 \\
\hline Total white matter & $577.12(77.65)$ & $576.26(70.28)$ & 0.38 & 0.82 & 1,11 \\
\hline Total CSF & $158.26(42.42)$ & $216.20(105.37)$ & $0.028^{*}$ & 6.38 & 1,11 \\
\hline
\end{tabular}

CSF, Cerebrospinal fluid.

${ }^{*} p<0.05, * * p<0.01$.

COMT, gender or COMT $\times$ gender interactions were found in the volume of any other brain region or ventricles (Table 2). After correction for multiple comparisons $(p<0.0045)$ only frontal lobe volumes remained significantly different, with larger volumes in the val-hemizygous group compared with the methemizygous group.

\section{COMT effects on total tissue class volumes}

Having accounted for total intracranial volume and age, there was no gender effect on total CSF, grey, and white matter volume. There was a significant COMT effect on total CSF volume ( $p=0.028, F=6.38)$. In addition there was a significant COMT $\times$ gender interaction on total white matter volume $(p=0.015, F=8.31)$ and total CSF volume $(p=0.003, F=14.86)$ (Table 2). After correction for multiple comparisons $(p<0.017)$ only a COMT $\times$ gender interaction on CSF remained significant.

\section{COMT effects on regional grey matter distribution}

There was a significant difference between the VCFS Val-hemizygous and Met-hemizygous group in grey matter volume at four spatially extensive 3D voxel clusters. The Met-hemizygous group had a significant reduced grey matter volume in left parahippocampal gyrus and brainstem, and bilaterally in cerebellum. There were no significant clusters of
Table 3. Regional differences in grey and white matter volume

\begin{tabular}{|c|c|c|c|c|c|}
\hline \multirow[b]{2}{*}{ Cerebral region } & \multirow[b]{2}{*}{$n$} & \multicolumn{3}{|c|}{$\begin{array}{l}\text { Talairach } \\
\text { coordinates }(\mathrm{mm})\end{array}$} & \multirow[b]{2}{*}{ Side } \\
\hline & & $\mathrm{x}$ & $\mathrm{y}$ & z & \\
\hline \multicolumn{6}{|l|}{ Grey matter } \\
\hline Met $<$ Val & Deficit & & & & \\
\hline Cerebellum & 2948 & 9.3 & -65.1 & -19.4 & $\mathrm{R}$ \\
\hline Cerebellum & 116 & -34.3 & 59.3 & -16.6 & $\mathrm{~L}$ \\
\hline Brainstem & 10 & -11.0 & -36.8 & -26.0 & $\mathrm{~L}$ \\
\hline $\begin{array}{l}\text { Parahippo- } \\
\text { campal gyrus }\end{array}$ & 208 & -21.9 & 46.5 & -4.8 & $\mathrm{~L}$ \\
\hline \multicolumn{6}{|l|}{ White matter } \\
\hline Met $>$ Val & Excess & & & & \\
\hline Cerebellum & 4776 & 7.2 & -57.8 & 21.4 & $\mathrm{R}$ \\
\hline
\end{tabular}

$n$, Number of voxels in each cluster.

The cluster-wise probability is $p=0.001$.

excess grey matter in the Met-hemizygous group (Table 3, Fig. 2).

\section{COMT effects on regional white matter distribution}

The Met-hemizygous group had a significantly increased white matter volume in cerebellum. There were no clusters of reduced white matter in the Met-hemizygous group (Table 3, Fig. 3). 


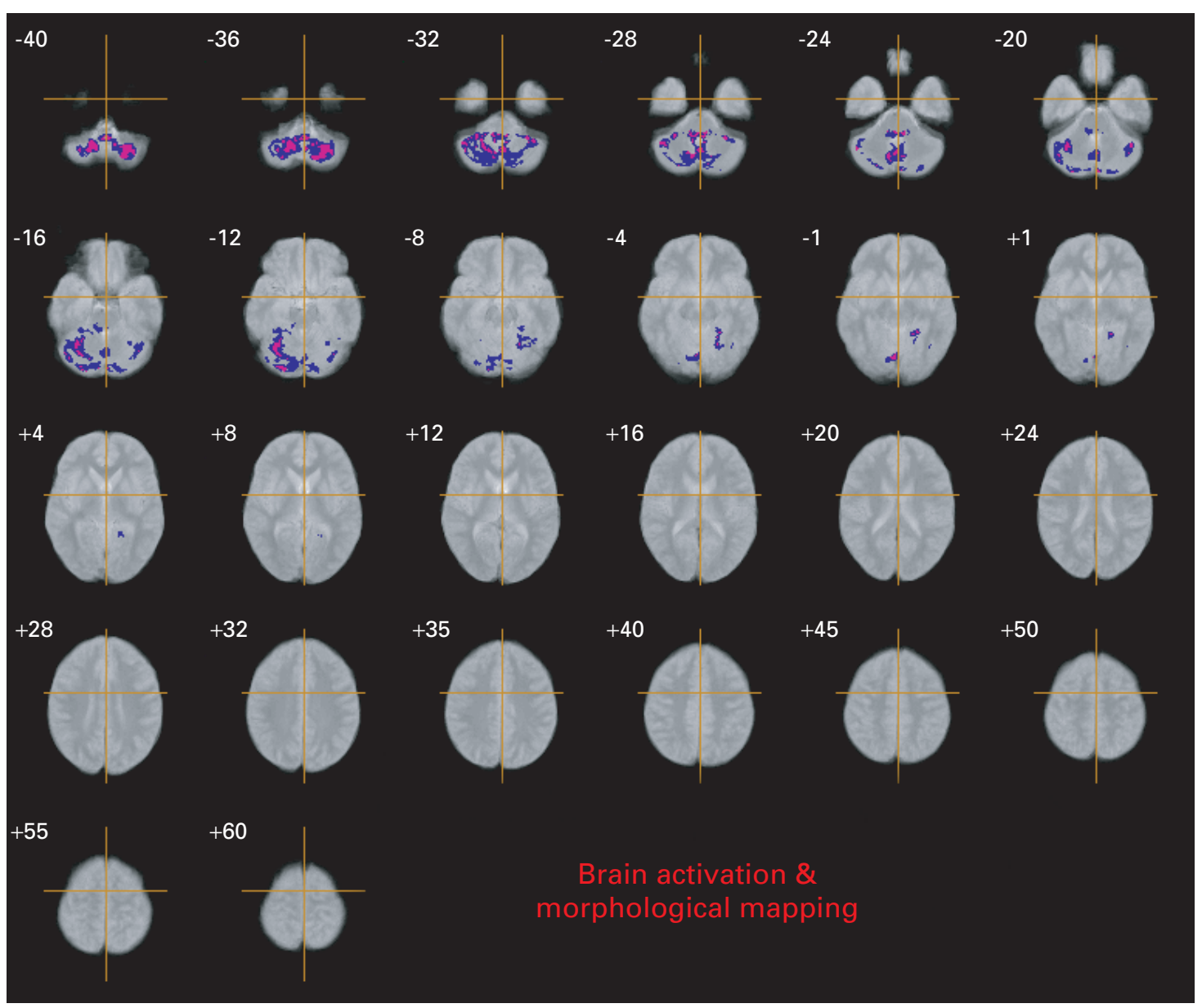

Fig. 2. Relative deficits (blue) and excesses (red) in grey matter volume in Met hemizygous compared with Val hemizygous VCFS people. The maps are oriented with the right side of the brain shown on the left side of each panel. The $\mathrm{z}$ coordinate for each row of axial slices in the standard space of Talairach \& Tournoux (1988) is given in millimetres.

\section{COMT effects on cognitive variables}

Accounting for age, there were significant COMT effects on two subtests of the Continuous Performance Test: Variability of Standard Error $(p=0.031, F=5.64)$, and Standard Error Block Change ( $p=0.023, F=6.42)$. Also there was a significant COMT effect on total CPT index score $(p=0.019, F=6.85)$ and on the minimal amount of moves needed (MAM) in the Tower of London task $(p=0.019, F=6.96)$ (Table 4).

Significant COMT $\times$ gender interactions were found for Standard Error Block Change of the CPT ( $p=0.011$, $F=8.42)$, Strategy Formation $(p=0.009, F=8.76)$ and Between Search Errors $(p=0.017, F=6.95)$ on the Golf Spatial Working Memory task, MAM of the Tower of London task $(p=0.006, F=10.16)$, Delayed Logical Memory of Wechsler memory Scale revised $(p=0.021$, $F=6.78$ ), Object Discrimination subtest of VOSP $(p=0.018, F=6.79)$. After Bonferroni correction for multiple comparisons none of the findings remained significant.

\section{Discussion}

We found that in adults with VCFS, the COMT $\mathrm{Val}^{158} \mathrm{Met}$ polymorphism is associated with significant differences in brain anatomy affecting frontal lobe volume and grey matter density in cerebellum, brainstem and parahippocampal gyrus, and white matter density in cerebellum.

However, our study has limitations. These include the relatively small sample size with insufficient power to look for interactions, and the multiple testing we carried out. Nevertheless, corrections for multiple comparisons were applied for all anatomical and cognitive variables. Also it is unlikely that differences in age, psychiatric comorbidity, and gender can fully account for our findings (as these factors did not differ between Val- and Met-hemizygous groups). In addition, we controlled for gender and age in the statistical analysis. Also, as noted by others (Chow et al. 1999), the effect size for structural brain abnormalities in people with VCFS is relatively large. Nevertheless 


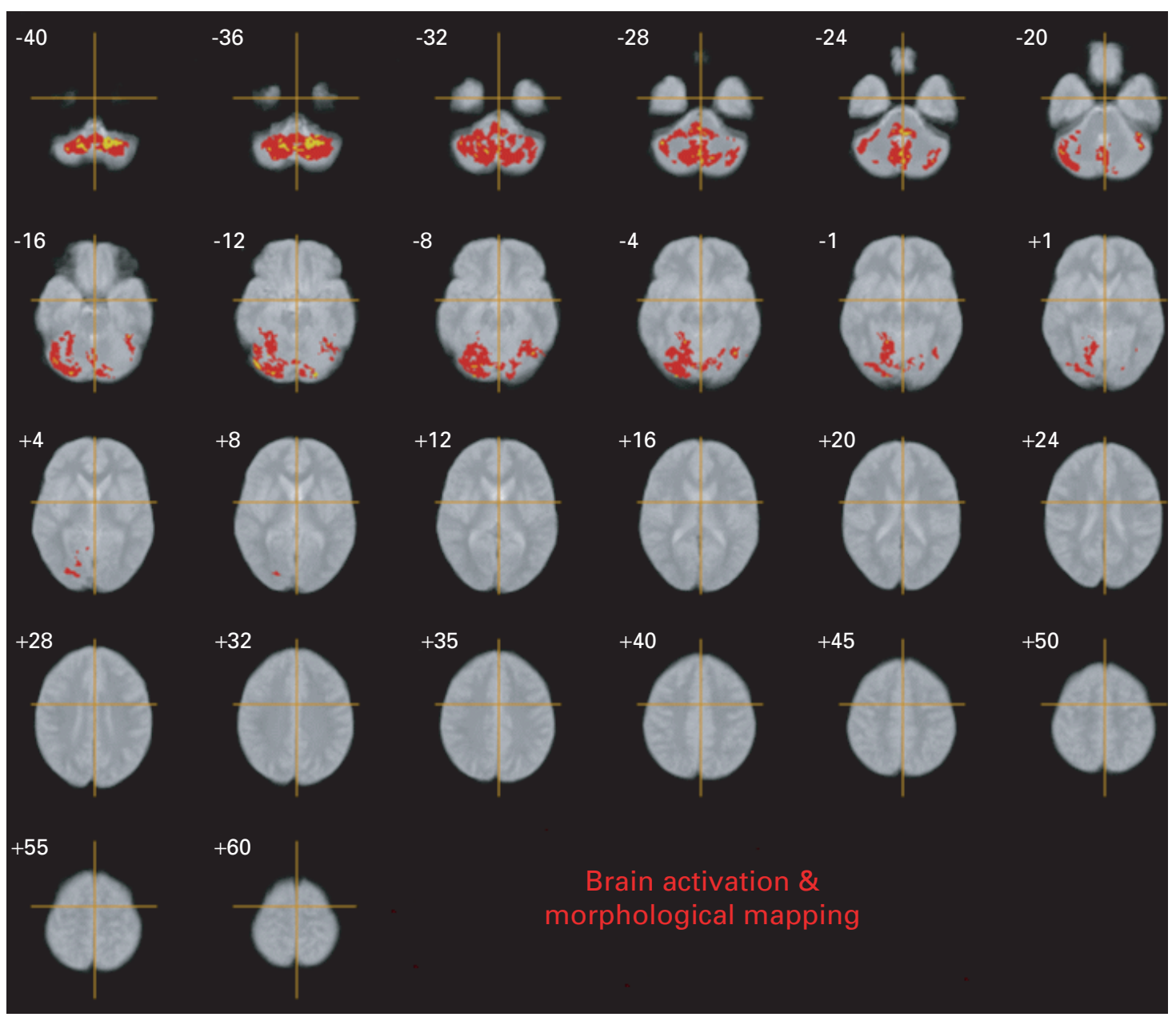

Fig. 3. Relative deficits (blue) and excesses (red) in white matter volume in Met hemizygous compared with Val hemizygous velo-cardio-facial syndrome people. The maps are oriented with the right side of the brain shown on the left side of each panel. The z coordinate for each row of axial slices in the standard space of Talairach \& Tournoux (1988) is given in millimetres.

our findings should be interpreted with caution and further studies of a longitudinal nature using larger samples of people with and without VCFS are required.

Our study is the first to demonstrate that the effect of the COMT Val ${ }^{158}$ Met polymorphism is not limited to frontal brain regions in people with VCFS. Because of the paucity of dopamine transporters in the prefrontal cortex, COMT is responsible for dopamine degradation in this region (Chen et al. 2004). Therefore, effects of the COMT $\mathrm{Val}^{158} \mathrm{Met}$ polymorphism on brain volume have previously been hypothesized to be most pronounced in frontal cortex, and this has been the focus of most studies on brain anatomy and COMT Val ${ }^{158} \mathrm{Met}$ polymorphism (Ho et al. 2005). Our results, using a whole brain anatomy approach, suggest that COMT Val ${ }^{158} \mathrm{Met}$ polymorphism may affect other brain regions as well, including cerebellum, a region particularly compromised in VCFS (Van Amelsvoort et al. 2004a; Simon et al. 2005; Campbell et al. 2006). COMT mRNA is expressed in several human brain regions including the frontal, temporal, and parietal lobes, and cerebellum, amygdala, putamen, thalamus and spinal cord (Hong et al. 1998). Therefore it is not surprising that the $\mathrm{Val}^{158} \mathrm{Met}$ polymorphism affects other brain regions than the PFC, which supports our findings. Also, COMT may be crucial for dopaminergic degradation in PFC, but more relevant for regulating norepinephrine (another substrate of COMT) in other brain regions. Both these neurochemical systems affect brain development and function. Thus COMT $\mathrm{Val}^{158} \mathrm{Met}$ effects on brain anatomy may not only reflect differences in dopamine degradation but also differences in (nor)epinephrine metabolism (Parini et al. 1988).

The underlying biological mechanism for our finding of larger bulk frontal lobe volumes and increased grey matter densities in Val-hemizygotes is unclear. 
Table 4. Neuropsychological test scores for velo-cardio-facial syndrome Met and Val subgroups

\begin{tabular}{|c|c|c|c|c|c|}
\hline & Val & Met & $p$ value & $F$ & $\mathrm{df}$ \\
\hline \multicolumn{6}{|l|}{ Intellectual functioning } \\
\hline WAIS-R & $(n=12)$ & $(n=11)$ & & & 1,18 \\
\hline Vocabulary & $4.58 \pm 2.19$ & $4.18 \pm 2.23$ & 0.27 & 1.27 & \\
\hline Comprehension & $4.42 \pm 1.44$ & $4.45 \pm 1.51$ & 0.33 & 1.00 & \\
\hline Similarities & $5.58 \pm 0.79$ & $4.91 \pm 1.97$ & 0.14 & 2.36 & \\
\hline Block Design & $5.75 \pm 3.38$ & $6.00 \pm 2.90$ & 0.58 & 0.32 & \\
\hline Object Assembly & $4.83 \pm 2.66$ & $4.64 \pm 3.04$ & 0.41 & 0.71 & \\
\hline VIQ & $73.25 \pm 7.59$ & $71.36 \pm 9.80$ & 0.22 & 1.61 & \\
\hline PIQ & $73.58 \pm 15.97$ & $77.36 \pm 18.42$ & 0.24 & 0.63 & \\
\hline FSIQ & $71.67 \pm 10.55$ & $72.32 \pm 13.21$ & 0.38 & 0.82 & \\
\hline V-P Discrepancy & $-0.33 \pm 12.57$ & $-6.0 \pm 12.18$ & 0.80 & 0.06 & \\
\hline \multicolumn{6}{|l|}{ Memory } \\
\hline Doors and People & $(n=12)$ & $(n=9)$ & & & 1,16 \\
\hline People & $5.58 \pm 3.32$ & $5.22 \pm 2.73$ & 0.25 & 1.44 & \\
\hline Doors & $3.92 \pm 2.02$ & $5.78 \pm 3.77$ & 0.93 & 0.01 & \\
\hline Shapes & $5.08 \pm 4.23$ & $6.11 \pm 3.92$ & 0.68 & 0.18 & \\
\hline Names & $6.67 \pm 5.23$ & $6.44 \pm 3.84$ & 0.39 & 0.80 & \\
\hline Overall & $3.33 \pm 3.55$ & $4.88 \pm 4.02$ & 0.67 & 0.20 & \\
\hline Visual & $4.27 \pm 2.49$ & $6.38 \pm 3.54$ & 0.96 & 0.00 & \\
\hline Verbal & $5.67 \pm 4.56$ & $6.25 \pm 3.01$ & 0.50 & 0.47 & \\
\hline Recall & $4.67 \pm 3.28$ & $5.62 \pm 2.77$ & 0.37 & 0.86 & \\
\hline Recognition & $4.64 \pm 3.38$ & $6.13 \pm 4.12$ & 0.81 & 0.06 & \\
\hline Overall Forgetting & $10.50 \pm 4.54$ & $11.22 \pm 2.82$ & 0.78 & 0.08 & \\
\hline WMS-R & $(n=11)$ & $(n=9)$ & & & 1,15 \\
\hline Logical Memory Immediate & $23.09 \pm 11.26$ & $20.89 \pm 13.0$ & 0.19 & 1.90 & \\
\hline Logical Memory Delayed & $6.18 \pm 5.83$ & $5.50 \pm 4.84$ & 0.14 & 2.49 & \\
\hline Paired Associates Immediate & $12.36 \pm 5.45$ & $13.89 \pm 6.86$ & 0.76 & 0.09 & \\
\hline Paired Associates Delayed & $10.0 \pm 5.51$ & $12.00 \pm 5.45$ & 0.97 & 0.00 & \\
\hline Verbal Memory Index & $67.82 \pm 16.6$ & $71.13 \pm 12.92$ & 0.48 & 0.08 & \\
\hline \multicolumn{6}{|l|}{ Visuospatial/perceptual functioning } \\
\hline VOSP & $(n=12)$ & $(n=11)$ & & & 1,18 \\
\hline Incomplete Letters & $19.33 \pm 0.65$ & $19.00 \pm 2.10$ & 0.26 & 1.33 & \\
\hline Silhouettes & $13.83 \pm 2.79$ & $17.09 \pm 4.91$ & 0.13 & 2.49 & \\
\hline Object Decision & $13.67 \pm 3.17$ & $14.82 \pm 4.45$ & 0.79 & 0.07 & \\
\hline Progressive Silhouettes & $12.75 \pm 2.60$ & $11.09 \pm 2.59$ & 0.59 & 0.30 & \\
\hline Dot Counting & $9.75 \pm 0.45$ & $9.82 \pm 0.41$ & 0.95 & 0.00 & \\
\hline Position Discrimination & $16.00 \pm 3.79$ & $17.55 \pm 2.77$ & 0.58 & 0.34 & \\
\hline Number Location & $6.58 \pm 3.50$ & $6.09 \pm 3.18$ & 0.53 & 0.40 & \\
\hline Cube Analysis & $6.83 \pm 2.86$ & $6.18 \pm 2.52$ & 0.45 & 0.59 & \\
\hline Number of Passes & $4.75 \pm 1.29$ & $5.55 \pm 1.75$ & 0.62 & 0.25 & \\
\hline \multicolumn{6}{|l|}{ Spatial Working Memory } \\
\hline Executive Golf Task & $(n=12)$ & $(n=11)$ & & & 1,18 \\
\hline Within Search Errors & $0.60 \pm 0.85$ & $0.91 \pm 0.91$ & 0.38 & 0.82 & \\
\hline Between Search Errors & $4.63 \pm 2.16$ & $5.69 \pm 2.64$ & 0.10 & 3.07 & \\
\hline Strategy Formation & $12.35 \pm 1.16$ & $12.55 \pm 1.12$ & 0.32 & 1.06 & \\
\hline \multicolumn{6}{|l|}{ Planning and Problem-Solving } \\
\hline Tower of London & $(n=12)$ & $(n=9)$ & & & 1,16 \\
\hline Moves Above Minimum & $2.74 \pm 1.04$ & $2.02 \pm 1.35$ & $0.03^{*}$ & 5.89 & \\
\hline Planning (s) & $4.09 \pm 1.94$ & $4.56 \pm 2.41$ & 0.24 & 1.51 & \\
\hline Verbal fluency & $(n=12)$ & $(n=7)$ & & & 1,14 \\
\hline Total & $22.17 \pm 9.52$ & $23.43 \pm 15.70$ & 0.25 & 1.47 & \\
\hline Weigl & $(n=12)$ & $(n=10)$ & & $\chi^{2}$ & \\
\hline Sorting & $100 \%$ & $90 \%$ & 0.45 & 1.59 & \\
\hline Shifting & $33.3 \%$ & $60 \%$ & 0.53 & 1.28 & \\
\hline
\end{tabular}


Table 4 (cont.)

\begin{tabular}{lllll}
\hline & Val & Met & $p$ value & $F$ \\
\hline Attention & & & & \\
$\quad$ CPT (T scores) & $(n=12)$ & $(n=9)$ & & \\
$\quad$ Ommission Errors (percentiles) & $96.85 \pm 4.44$ & $95.74 \pm 6.36$ & 0.71 & 0.14 \\
$\quad$ Hit Reaction Times (T scores) & $40.70 \pm 7.32$ & $43.97 \pm 8.39$ & 0.19 & 1.91 \\
$\quad$ Variablility of s.E.'s (T scores) & $69.11 \pm 14.78$ & $75.02 \pm 11.99$ & $0.02^{*}$ & 6.20 \\
Hit s.E. Block Change (T scores) & $59.76 \pm 14.66$ & $45.41 \pm 22.95$ & $0.02^{*}$ & 7.11 \\
Commission Errors (T scores) & $62.05 \pm 13.21$ & $61.23 \pm 14.14$ & 0.67 & 0.19 \\
Perceptual Sensitivity (T scores) & $71.28 \pm 11.32$ & $69.58 \pm 11.01$ & 0.59 & 0.31 \\
Risk Taking (T scores) & $83.28 \pm 15.30$ & $82.22 \pm 18.41$ & 0.46 & 0.58 \\
CPT Index Score & $10.50 \pm 4.19$ & $12.50 \pm 3.99$ & $0.04^{*}$ & 5.28 \\
\hline
\end{tabular}

Values are group means \pm S.D.

${ }^{*} p<0.05$.

One possible explanation could be differences in brain maturation between the two genotype groups. Qualitative imaging studies have reported brain anomalies in children and adults with VCFS, for example agenesis of the corpus callosum, white matter hyperintensities and septum pellucidum abnormalities (Mitnick et al. 1994; Chow et al. 1999; Van Amelsvoort et al. 2001). Quantitative imaging studies have also reported evidence for disturbed brain maturation in people with VCFS. For example, several studies of brain anatomy have reported that people with VCFS compared with controls often have abnormalities in either frontal lobe anatomy (with subtle differences in grey/white matter composition) and/or posterior brain regions including cerebellum (Van Amelsvoort et al. 2004a; Simon et al. 2005; Campbell et al. 2006). Normal brain maturation starts from posterior/inferior brain regions and takes place last in frontal regions (Sowell et al. 1999) and is associated with an increase in frontal white matter and a decrease in grey matter during adolescence (Nagy et al. 2004). Abnormalities in brain maturation (e.g. programmed cell death) could therefore lead to differences in the relative proportions of grey and white matter and hence frontal lobe volume. Since normal brain maturation is accompanied by increasingly efficient cognitive processing (Levy \& Goldman-Rakic, 2000), the finding of decreased efficiency of prefrontal cognitive processing in those possessing the Val allele (Egan et al. 2001) perhaps suggests that possessing the Val allele may slow down the maturation process - and hence the relative proportion of grey and white matter and/ or bulk volume of frontal regions. A so-called anteriorposterior dichotomy in anatomical differences between people with VCFS and controls has been suggested (Kates et al. 2001; Van Amelsvoort et al. 2004a; Simon et al. 2005), and could also explain differences in brain anatomy within the VCFS population between those hemizygous for $\mathrm{Val}$ or Met. How COMT haploinsufficiency in VCFS affects the dopaminergic system is still unknown, although a preliminary open study by Graf et al. (2001) suggested increased baseline brain dopamine levels in three of four patients with VCFS and the Met-allele, as measured by the level of a catecholamine metabolite, homovanillic acid, in cerebrospinal fluid compared with calibrated standards and laboratory controls. These preliminary findings suggest that haploinsufficiency in COMT is associated with dysregulation of dopaminergic systems. Results from animal and human studies suggest that dopamine has a trophic action during early brain maturation and later influences prefrontal cortical specification (Nieoullon, 2002). Therefore, differences in dopaminergic clearance as a result of $\mathrm{Val}$ - or Met-hemizygosity could result in differences in (frontal) brain maturation because of differences in dopamine signalling during early brain development. Our finding of relative cerebellar grey matter increase and white matter decrease in the Val-hemizygotes suggests that dynamic interplay between grey and white matter tissue composition might take place during brain maturation with grey matter volume decrease due to pruning and white matter volume increase during myelination. These findings further support the hypothesis that brain maturation may be slower in val-hemizygotes than in met-hemizygotes.

Our findings on cognitive performance did not survive Bonferroni corrections for multiple comparisons. This is probably partially due to our small sample size. The current literature suggests that cognitive tasks classically thought to be measures of 'frontal' regions are modulated by the COMT polymorphism. As mentioned before the results on COMT polymorphism and cognitive function in VCFS are 
inconsistent also because various study groups have used different cognitive measures and study populations included people of different ages. Future studies with larger sample sizes and of a longitudinal nature should clarify the role of the COMT polymorphism on specific cognitive tasks during lifespan in VCFS.

In conclusion, our results suggest that genetic variation in COMT activity affects brain anatomy in adults with VCFS, and this extends outside frontal brain regions. This suggests variation in COMT activity is implicated in brain development in VCFS. Future studies are required to investigate changes across the lifespan.

\section{Declaration of Interest}

None.

\section{References}

Akil M, Kolachana BS, Rothmond DA, Hyde TM, Weinberger DR, Kleinman JE (2003). Catechol-Omethyltransferase genotype and dopamine regulation in the human brain. Journal of Neuroscience 23, 2008-2013.

Andersen SL, Dumont NL, Teicher MH (1997). Developmental differences in dopamine synthesis inhibition by (+/-)-7-OH-DPAT. Naunyn Schmiedebergs Arch Pharmacol 356, 173-181.

APA (1994). Diagnostic and Statistical Manual of Mental Disorders, 4th edn (DSM-IV). American Psychiatric Association: Washington, DC.

Baddeley AD, Emslie H, Nimmo-Smith I (1994). The Doors and People Test: a Test of Visual and Verbal Recall and Recognition. Thames Valley Test Company: Bury St. Edmunds.

Baker K, Baldeweg T, Sivagnanasundaram S, Scambler P, Skuse D (2005). COMT Val108/158 Met modifies mismatch negativity and cognitive function in 22q11 deletion syndrome. Biological Psychiatry 58, 23-31.

Baker SC, Rogers RD, Owen AM, Frith CD, Dolan RJ, Frackowiak RS, Robbins TW (1996). Neural systems engaged by planning: a PET study of the Tower of London task. Neuropsychologia 34, 515-526.

Barta PE, Dhingra L, Royall R, Schwartz E (1997). Improving stereological estimates for the volume of structures identified in three-dimensional arrays of spatial data. Journal of Neuroscience Methods 75, 111-118.

Bassett AS, Caluseriu O, Weksberg R, Young DA, Chow EW (2007). Catechol-O-methyl transferase and expression of schizophrenia in 73 adults with 22q11 deletion syndrome. Biological Psychiatry. doi:10.1016/ j.biopsych.2006.07.038.

Bearden CE, Jawad AF, Lynch DR, Sokol S, Kanes SJ, McDonald-McGinn DM, Saitta SC, Harris SE, Moss E, Wang PP, Zackai E, Emanuel BS, Simon TJ (2004). Effects of a functional COMT polymorphism on prefrontal cognitive function in patients with 22q11.2 deletion syndrome. American Journal of Psychiatry 161, 1700-1702.
Benton AL, Hamsher KS (1976). Multilingual Aphasia Examination. University of Iowa: Iowa City, IA.

Brammer MJ, Bullmore ET, Simmons A, Williams SC, Grasby PM, Howard RJ, Woodruff PW, Rabe-Hesketh S (1997). Generic brain activation mapping in functional magnetic resonance imaging: a nonparametric approach. Magnetic Resonance Imaging 15, 763-770.

Bullmore E, Brammer M, Rouleau G, Everitt B, Simmons A, Sharma T, Frangou S, Murray R, Dunn G (1995). Computerized brain tissue classification of magnetic resonance images: a new approach to the problem of partial volume artifact. Neuroimage 2, 133-147.

Bullmore ET, Suckling J, Overmeyer S, Rabe-Hesketh S, Taylor E, Brammer MJ (1999). Global, voxel, and cluster tests, by theory and permutation, for a difference between two groups of structural MR images of the brain. IEEE Transactions on Medical Imaging 18, 32-42.

Campbell LE, Daly E, Toal F, Stevens A, Azuma R, Catani M, Ng V, Van Amelsvoort T, Chitnis X, Cutter W, Murphy DG, Murphy KC (2006). Brain and behaviour in children with 22q11.2 deletion syndrome: a volumetric and voxel-based morphometry MRI study. Brain 129, 1218-1228.

Chen J, Lipska BK, Halim N, Ma QD, Matsumoto M, Melhem S, Kolachana BS, Hyde TM, Herman MM, Apud J, Egan MF, Kleinman JE, Weinberger DR (2004). Functional analysis of genetic variation in catechol-O-methyltransferase (COMT): effects on mRNA, protein, and enzyme activity in postmortem human brain. American Journal of Human Genetics 75, 807-821.

Chow EW, Mikulis DJ, Zipursky RB, Scutt LE, Weksberg R, Bassett AS (1999). Qualitative MRI findings in adults with 22q11 deletion syndrome and schizophrenia. Biological Psychiatry 46, 1436-1442.

Conner CK (1995). Continuous Performance Test. Multi-Health Systems Inc.: Toronto, Canada.

Dunham I, Collins J, Wadey R, Scambler P (1992). Possible role for COMT in psychosis associated with velo-cardio-facial syndrome. Lancet 340 (8831), 1361-1362.

Egan MF, Goldberg TE, Kolachana BS, Callicott JH, Mazzanti CM, Straub RE, Goldman D, Weinberger DR (2001). Effect of COMT Val108/158 Met genotype on frontal lobe function and risk for schizophrenia. Proceedings of the National Academy of Sciences USA 98, 6917-6922.

Glaser B, Debbane M, Hinard C, Morris MA, Dahoun SP, Antonarakis SE, Eliez S (2006). No evidence for an effect of COMT Val158Met genotype on executive function in patients with 22q11 deletion syndrome. American Journal of Psychiatry 163, 537-539.

Goldstein KH, Scheerer M (1941). Abstract and concrete behaviour: an experimental study with special tests. Psychological Monographs 53, no. 2.

Gothelf D, Eliez S, Thompson T, Hinard C, Penniman L, Feinstein C, Kwon H, Jin S, Jo B, Antonarakis SE, Morris MA, Reiss AL (2005). COMT genotype predicts longitudinal cognitive decline and psychosis in 22q11.2 deletion syndrome. Nature Neuroscience 8, 1500-1502.

Graf WD, Unis AS, Yates CM, Sulzbacher S, Dinulos MB, Jack RM, Dugaw KA, Paddock MN, Parson WW (2001). 
Catecholamines in patients with 22q11.2 deletion syndrome and the low-activity COMT polymorphism. Neurology 57, 410-416.

Ho BC, Wassink TH, O'Leary DS, Sheffield VC, Andreasen NC (2005). Catechol-O-methyl transferase Val158Met gene polymorphism in schizophrenia: working memory, frontal lobe MRI morphology and frontal cerebral blood flow. Molecular Psychiatry 10, 287-298.

Hong J, Shu-Leong H, Tao X, Lap-Ping Y (1998). Distribution of catechol-O-methyltransferase expression in human central nervous system. Neuroreport 9, 2861-2864.

Kates WR, Antshel KM, AbdulSabur N, Colgan D, Funke B, Fremont W, Higgins AM, Kucherlapati R, Shprintzen RJ (2006). A gender-moderated effect of a functional COMT polymorphism on prefrontal brain morphology and function in velo-cardio-facial syndrome (22q11.2 deletion syndrome). American Journal of Medical Genetics, B: Neuropsychiatric Genetics 141, 274-280.

Kates WR, Burnette CP, Jabs EW, Rutberg J, Murphy AM, Grados M, Geraghty M, Kaufmann WE, Pearlson GD (2001). Regional cortical white matter reductions in velocardiofacial syndrome: a volumetric MRI analysis. Biological Psychiatry 49, 677-684.

Lachman HM, Papolos DF, Saito T, Yu YM, Szumlanski CL, Weinshilboum RM (1996). Human catechol-Omethyltransferase pharmacogenetics: description of a functional polymorphism and its potential application to neuropsychiatric disorders. Pharmacogenetics 6, 243-250.

Levy R, Goldman-Rakic PS (2000). Segregation of working memory functions within the dorsolateral prefrontal cortex. Experimental Brain Research 133, 23-32.

Malhotra AK, Kestler LJ, Mazzanti C, Bates JA, Goldberg T, Goldman D (2002). A functional polymorphism in the COMT gene and performance on a test of prefrontal cognition. American Journal of Psychiatry 159, 652-654.

McAlonan GM, Daly E, Kumari V, Critchley HD, Van Amelsvoort T, Suckling J, Simmons A, Sigmundsson T, Greenwood K, Russell A, Schmitz N, Happe F, Howlin P, Murphy DG (2002). Brain anatomy and sensorimotor gating in Asperger's syndrome. Brain 125, 1594-1606.

Meyer-Lindenberg A, Kohn PD, Kolachana B, Kippenhan S, McInerney-Leo A, Nussbaum R, Weinberger DR, Berman KF (2005). Midbrain dopamine and prefrontal function in humans: interaction and modulation by COMT genotype. Nature Neuroscience 8, 594-596.

Mitnick RJ, Bello JA, Shprintzen RJ (1994). Brain anomalies in velo-cardio-facial syndrome. American Journal of Medical Genetics 54, 100-106.

Morris RG, Downes JJ, Robbins TW (1990). The nature of the dysexecutive syndrome in Parkinson's disease. In Lines of Thinking (ed. K.J. Gilhooly, M.T.G. Keane, R.H. Logie and G. Erdos), pp. 247-258. John Wiley: New York.

Morris RG, Downes JJ, Sahakian BJ, Evenden JL, Heald A, Robbins TW (1988). Planning and spatial working memory in Parkinson's disease. Journal of Neurology, Neurosurgery \& Psychiatry 51, 757-766.

Murphy DG, DeCarli CD, Daly E, Gillette JA, McIntosh AR, Haxby JV, Teichberg D, Schapiro MB, Rapoport SI, Horwitz B (1993b). Volumetric magnetic resonance imaging in men with dementia of the Alzheimer type: correlations with disease severity. Biological Psychiatry 34, 612-621.

Murphy DG, DeCarli C, Daly E, Haxby JV, Allen G, White BJ, McIntosh AR, Powell CM, Horwitz B, Rapoport SI (1993a). X-chromosome effects on female brain: a magnetic resonance imaging study of Turner's syndrome. Lancet 342, 1197-1200.

Murphy DG, DeCarli C, Schapiro MB, Rapoport SI, Horwitz B (1992). Age-related differences in volumes of subcortical nuclei, brain matter, and cerebrospinal fluid in healthy men as measured with magnetic resonance imaging. Archives of Neurology 49, 839-845.

Murphy KC, Jones LA, Owen MJ (1999). High rates of schizophrenia in adults with velo-cardio-facial syndrome. Archives of General Psychiatry 56, 940-945.

Nagy Z, Westerberg H, Klingberg T (2004). Maturation of white matter is associated with the development of cognitive functions during childhood. Journal of Cognitive Neurosciences 16, 1227-1233.

Nieoullon A (2002). Dopamine and the regulation of cognition and attention. Progress in Neurobiology 67, 53-83.

Papolos DF, Faedda GL, Veit S, Goldberg R, Morrow B, Kucherlapati R, Shprintzen RJ (1996). Bipolar spectrum disorders in patients diagnosed with velo-cardio-facial syndrome: does a hemizygous deletion of chromosome 22q11 result in bipolar affective disorder? American Journal of Psychiatry 153, 1541-1547.

Parini A, Coupry I, Laude D, Diop L, Vincent M, Sassard J, Dausse JP (1988). Noradrenaline content and adrenergic receptors in kidney and heart of the prehypertensive and hypertensive Lyon rat strain. American Journal of Hypertension 1, 140-145.

Press WH, Taukolsy SA, Vetterling WT, Flannery BP (1992). Numerical Recipes in C: The Art of Scientific Computing, 2nd edn. Cambridge University Press: Cambridge.

Shallice T (1982). Specific impairments of planning. Philosophical Transactions of the Royal Society (London) 298, 199-209.

Shashi V, Keshavan MS, Howard TD, Berry MN, Basehore MJ, Lewandowski E, Kwapil TR (2006). Cognitive correlates of a functional COMT polymorphism in children with 22q11.2 deletion syndrome. Clinical Genetics 69, 234-238.

Shprintzen RJ, Goldberg RB, Lewin ML, Sidoti EJ, Berkman MD, Argamaso RV, Young D (1978). A new syndrome involving cleft palate, cardiac anomalies, typical facies, and learning disabilities: velo-cardio-facial syndrome. Cleft Palate Journal 15, 56-62.

Sigmundsson T, Suckling J, Maier M, Williams S, Bullmore E, Greenwood K, Fukuda R, Ron M, Toone B (2001). Structural abnormalities in frontal, temporal, and limbic regions and interconnecting white matter tracts in schizophrenic patients with prominent negative symptoms. American Journal of Psychiatry 158, 234-243.

Simon TJ, Ding L, Bish JP, McDonald-McGinn DM, Zackai EH, Gee J (2005). Volumetric, connective, and morphologic changes in the brains of children with chromosome 22q11.2 deletion syndrome: an integrative study. Neuroimage 25, 169-180. 
Smolka MN, Schumann G, Wrase J, Grusser SM, Flor H, Mann K, Braus DF, Goldman D, Buchel C, Heinz A (2005). Catechol-O-methyltransferase val158met genotype affects processing of emotional stimuli in the amygdala and prefrontal cortex. Journal of Neuroscience $\mathbf{2 5}$ 836-842.

Sowell ER, Thompson PM, Holmes CJ, Jernigan TL, Toga AW (1999). In vivo evidence for post-adolescent brain maturation in frontal and striatal regions. Nature Neuroscience 2, 859-861.

Suckling J, Brammer MJ, Lingford-Hughes A, Bullmore ET (1999a). Removal of extracerebral tissues in dual-echo magnetic resonance images via linear scale-space features. Magnetic Resonance Imaging 17, 247-256.

Suckling J, Sigmundsson T, Greenwood K, Bullmore ET (1999b). A modified fuzzy clustering algorithm for operator independent brain tissue classification of dual echo MR images. Magnetic Resonance Imaging 17, 1065-1076.

Talairach J, Tournoux P (1988). Co-Planar Stereotaxic Atlas of the Human Brain. Thieme Medical Publishers: New York.

Tunbridge EM, Harrison PJ, Weinberger DR (2006). Catechol-o-methyltransferase, cognition, and psychosis: Val(158)Met and beyond. Biological Psychiatry 60, 141-151.

Van Amelsvoort T, Daly E, Henry J, Robertson D, Ng V, Owen M, Murphy KC, Murphy DG (2004a). Brain anatomy in adults with velocardiofacial syndrome with and without schizophrenia: preliminary results of a structural magnetic resonance imaging study. Archives of General Psychiatry 61, 1085-1096.

Van Amelsvoort T, Daly E, Robertson D, Suckling J, Ng V, Critchley H, Owen MJ, Henry J, Murphy KC, Murphy DG (2001). Structural brain abnormalities associated with deletion at chromosome 22q11: quantitative neuroimaging study of adults with velo-cardio-facial syndrome. British Journal of Psychiatry 178, 412-419.

Van Amelsvoort T, Henry J, Morris R, Owen M, Linszen D, Murphy K, Murphy D (2004b). Cognitive deficits associated with schizophrenia in velo-cardio-facial syndrome. Schizophrenia Research 70, 223-232.

Wahlstrom D, White T, Hooper CJ, Vrshek-Schallhorn S, Oetting WS, Brott MJ, Luciana M (2007). Variations in the catechol O-methyltransferase polymorphism and prefrontally guided behaviors in adolescents. Biological Psychiatry 61, 626.

Warrington EK, James M (1991). The Visual Object and Space Perception Battery. Thames Valley Test Company: Titchfield, UK.

Wechsler D (1981). The Wechsler Adult Intelligence Scale-Revised. Psychological Corporation: New York.

Wechsler D (1987). Wechsler Memory Scale - Revised: Manual. The Psychological Corporation: San Antonio, TX.

Wing JK, Babor T, Brugha T, Burke J, Cooper JE, Giel R, Jablenski A, Regier D, Sartorius N (1990). SCAN. Schedules for Clinical Assessment in Neuropsychiatry. Archives of General Psychiatry 47, 589-593. 